\title{
Controlled release of 1-hydroxyethylidene diphosphonate: in vitro assessment and effects on bioprosthetic calcification in sheep tricuspid valve replacements
}

\author{
Thomas P. Johnston ${ }^{1}$, Edward L. Bove ${ }^{1}$, Steven F. Bolling ${ }^{1}$, James A. Boyd ${ }^{1}$, \\ Barbara L. Ciesliga ${ }^{1}$, Gordon L. Amidon ${ }^{1}$, Frederick J. Schoen ${ }^{2}$ and Robert J. Levy ${ }^{1}$ \\ ${ }^{I}$ Department of Pediatrics and Communicable Disease and Section of Thoracic Surgery, Division of Pediatric Cardiology, C.S. Mott \\ Children's Hospital, and Department of Pharmaceutics, College of Pharmacy, The University of Michigan, Ann Arbor, MI 48109 (U.S.A.) \\ and ${ }^{2}$ Department of Pathology, Brigham and Women's Hospital and Harvard Medical School, Boston, MA O2115 (U.S.A.)
}

(Received 17 June 1988)

(Modified version received 11 November 1988)

(Accepted 14 November 1988)

Key words: Ethanehydroxydiphosphonate; Bioprosthetic heart valve calcification; Controlled release; Silicone rubber

\section{Summary}

Calcification (CALC) is the most frequent cause of the clinical failure of bioprosthetic valves (BHV's). Controlled-release (paravalvar) administration of the anticalcification agent ethanehydroxydiphosphonate (EHDP), as either $\mathrm{Na}_{2} \mathrm{EHDP}_{\text {or in combina- }}$ tion $(1: 1)$ with the less soluble CaEHDP, from a silicone rubber matrix (20\% $\mathrm{w} / \mathrm{w}$ EHDP) was studied both in vitro and in vivo for the prevention of BHV CALC. Seventeen sheep (6-7 months old, male, Suffolk) underwent tricuspid valve replacement using Hancock I, $25 \mathrm{~mm}$ porcine aortic bioprostheses. BHV explant evaluation after 16-20 weeks revealed that two of the 7 control BHV were calcified (139 $\pm 20.8 \mu \mathrm{g} \mathrm{Ca}^{2+} / \mathrm{mg}$ of tissue), while none of the $9 \mathrm{BHV}$ retrieved from animals receiving controlled release EHDP demonstrated CALC (4.41 $\pm 1.09 \mu \mathrm{g} \mathrm{Ca}{ }^{2+} / \mathrm{mg}$ of tissue). No adverse effects of EHDP on bone or calcium metabolism were noted. The cumulative percent of EHDP released per electron microprobe analysis was $40.4 \% \pm 9.68(\mathrm{Na}, \mathrm{CaEHDP})$ to $79.0 \% \pm 4.82$ $\left(\mathrm{Na}_{2} \mathrm{EHDP}\right.$ ) in vivo compared to $35.7 \% \pm 7.72$ and $78.6 \pm 11.1$ in vitro, respectively. Assessment of the Young's modulus (Y) using thermomechanical analysis (TMA) revealed a 1.5-fold (Silastic Q7-4840) to 9.5-fold (Silastic 382) increase in $Y$ following drug loading. The $\mathrm{Y}$ for explanted, Silastic $\mathrm{Q} 7-4840$ polymer matrices ranged from $2.84 \times 10^{4}$ to $5.57 \times 10^{5} \mathrm{dyne} / \mathrm{cm}^{2}$. In vitro osmotic related matrix swelling of the $\mathrm{Na}_{2} \mathrm{EHDP}$ loaded, unsealed matrices $(20 \% \mathrm{w} / \mathrm{w})$ after 75 days was minimized to a $35.8 \%$ increase in weight due to coincorporation of CaEHDP with $\mathrm{Na}_{2}$ EHDP in a $1: 1$ ratio and was further reduced $(22.2 \%$ increase in weight) by sealing $76 \%$ of the releasing surface, compared to $\mathrm{Na}_{2}$ EHDP matrices which demonstrated a $414 \%$ and $141 \%$ increase in weight, respectively.

Correspondence: R.J. Levy, Division of Pediatric Cardiology, C.S. Mott Children's Hospital, The University of Michigan Medical Center, Kresge II Research Laboratories, Room 5-014, Ann Arbor, MI 48109-0576, U.S.A.

\section{Introduction}

Bioprosthetic heart valves (BHV) fabricated from either glutaraldehyde-preserved porcine aortic valve leaflets or pericardium have been 
widely used as replacements for diseased cardiac valves since 1970 (Barnhart et al., 1982a; Schoen and Levy, 1984; Schoen, 1987). However, the principal failure mode of $\mathrm{BHV}$ is sterile degeneration due to calcification (CALC) (Schoen and Levy, 1984; Schoen, 1987; Milano et al., 1984; Schoen and Hobson, 1985a). Despite the importance of this problem, the pathophysiology of BHV calcification is incompletely understood (Schoen et al., 1985b), and there are no satisfactory means for its prevention.

BHV CALC has been investigated in experimental animals using orthotopic valve replacements or conduit-mounted valves in sheep and calves (Barnhart et al., 1982b; Levy et al., 1983a; Thurbrikar et al., 1983; Gallo et al., 1987), and subcutaneous implants in mice (Levy et al., 1983b), rats (Levy et al., 1983c and 1985a), and rabbits (Fishbein et al., 1982). The subcutaneous and circulatory models simulate many of the pathologic features of long-term clinical implants.

Ethanehydroxydiphosphonate (EHDP) has been shown to effectively inhibit experimental BHV CALC (Levy et al., 1985b and c) but s.c. administration of EHDP to rats at doses greater than $15 \mathrm{mg} / \mathrm{kg} /$ day (Levy et al., 1987a) resulted in adverse effects on overall somatic growth, bone development, and serum $\mathrm{Ca}^{2+}$ levels. However, controlled release of EHDP from polymeric matrices coimplanted with BHV subdermally in rats prevented CALC without adverse effects by using minimal local doses [ $>0.1 \mathrm{mg} / \mathrm{kg} / 24 \mathrm{~h}$ ] (Levy et al., 1985b and c).

The purpose of the present study was to formulate EHDP controlled release matrices for implantation with orthotopic BHV in the circulation, assess their in vitro release, and in vivo efficacy and function. Thus, these experiments assessed: (1) the efficacy of the polymer-drug formulation with regard to inhibition of BHV CALC following tricuspid valve replacements in sheep, (2) the release profile of EHDP from the implanted matrix comparing in vitro to in vivo release, (3) the changes in viscoelastic properties of the polymer matrix resulting from drug loading and circulatory implantation, and (4) the magnitude of osmoticinduced matrix expansion.

\section{Materials and Methods}

Polydimethylsiloxane (Silastic 382), Silastic Q74840 and reinforced dacron Q7-4840 sheeting (plain weave, 0.007 in thick) were provided by Dow Corning (Midland, MI). Disodium 1,1-hydroxyethylidene diphosphonate ( $\mathrm{Na}_{2} \mathrm{EHDP}$ ) was provided by Norwich Eaton (Norwich, NY). The $\mathrm{Na}_{2}\left[{ }^{14} \mathrm{C}\right]$ EHDP (spec. act. $=48.9 \mu \mathrm{Ci} / \mathrm{mmol}$ ) and the calcium salt of EHDP were provided by Procter and Gamble, Inc. (Cincinatti, OH). Atom light scintillation solution was obtained from New England Nuclear (Billerica, MA).

\section{Controlled release matrices}

Carrier-free radiolabelled $\mathrm{Na}_{2}\left[{ }^{14} \mathrm{C}\right] \mathrm{EHDP}$, appropriately diluted with unlabelled $\mathrm{Na}_{2}$ EHDP to yield a specific activity of $1830 \mathrm{dpm} / \mu \mathrm{mol}$ EHDP, was levigated into polymer formulations for determining in vitro release of $\mathrm{Na}_{2} \mathrm{EHDP}$. For implants with calcium EHDP incorporated with $\mathrm{Na}_{2}$ EHDP, a $1: 1$ ratio of the two salts was used at the same total weight percentages as below. Circular (i.d. $=25 \mathrm{~mm}$, o.d. $=31 \mathrm{~mm}$ ) controlled release matrices were formulated by levigating disodium EHDP (90-106 $\mu \mathrm{m}$ particle size) into either Silastic 382 or Silastic Q7-4840 at a 20 or 30 wt. \% concentration.

A typical circular controlled release matrix is shown in Fig. 1. Each circular implant was fabricated with a wall thickness of $3 \mathrm{~mm}$. The height of the polymer-drug ring was $3.5 \mathrm{~mm}$, and sealing of all the surfaces $(76 \%$ of total available surface area) except the internal circumference with a non-drug-containing layer $(500 \mu \mathrm{m})$ of Silastic Q7-4840 or 382 resulted in a total initial releasing surface area of $2.75 \mathrm{~cm}^{2}$. Formulations fabricated from Silastic 382 were catalyzed by adding 2 drops of the catalyst (stannous octanoate) to $2 \mathrm{~g}$ of total formulation and then compression-molded under 2000 p.s.i. at room temperature in stainless-steel molds on a Carver Press equipped with heated platens (model C, Fred S. Carver, Inc., Menomonee Falls, WI). Controlled release matrices fabricated from Silastic Q7-4840 were compression-molded as above and heat-cured at $120^{\circ} \mathrm{C}$ Dacron-reinforced sheeting was thermally bonded $\left(T=120^{\circ} \mathrm{C}\right)$ to the top and bottom surface of the 


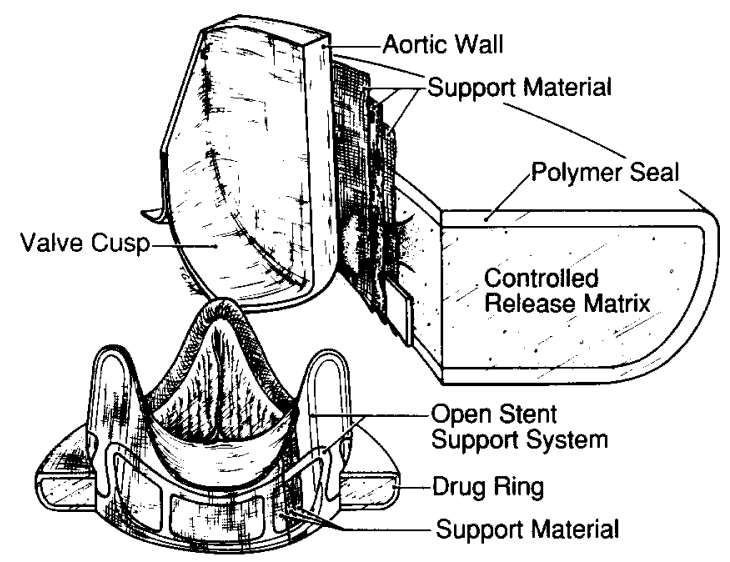

Fig. 1. A silicone rubber-EHDP controlled-release matrix positioned at the circumferential support of a porcine aortic bioprosthesis. Reproduced with permission from Replacement Cardiac Valves, Bodnar E. and Frater, R. (Eds.) Pergamon, Elmsford, NY, 1988.

polymer ring with plain polymer base. A typical matrix prior to implantation contained $149 \pm 8.69$ $\mathrm{mg}$ of EHDP.

\section{In vitro release of $E H D P$}

The release profiles of EHDP from silicone rubber drug delivery matrices were determined by calculating the diphosphonate-associated phosphorus (P) depleted from the polymer matrix as a function of time using electron microprobe analysis. Electron microprobe analysis was conducted using a Super 8000 Analyst equipped with a Kevex (Foster City, CA) system for elemental localization which was coupled with a scanning electron microscope (Hitachi, Model S-570, Santa Clara, CA). The Super 8000 Analyst and scanning electron microscope were acquired under Grant No. BSR-83-14092 from the National Science Foundation.

Matrices were incubated at $37^{\circ} \mathrm{C}$ in $20 \mathrm{ml}$ of a physiologic buffer $(0.10 \mathrm{M} \mathrm{NaCl}$ in $0.05 \mathrm{M}$ HEPES, $\mathrm{pH}=7.4$ ) and a center, cross-sectional cut of the matrix was obtained at $0,1,2,3,4$, and 5 months. The samples taken at the various time points were allowed to dry at room temperature before the analysis. The samples were mounted on stainlesssteel stubs and sputter-coated with carbon. Samples were analyzed for phosphorus and silicon.
Emitted X-rays for each element were collected for $1.5 \mathrm{~min}$. The counts associated with the area under a peak for each element were calculated by a deconvolution routine contained in the software program Quantex 1 (Mykelbust et al., 1979).

The amount of silicon in the silicone based polymers was used to normalize the phosphorus depletion by computing the ratio of the counts associated with the phosphorus peak to the counts observed for the silicon $(\mathrm{Si})$ peak for each sample at the above specified time points and were compared with a series of precisely formulated standards of known composition $(5 \%, 10 \%, 15 \%, 20 \%$, and $30 \% \mathrm{w} / \mathrm{w}$ EHDP in silicone rubber). The results obtained by microprobe analysis were also correlated with data obtained from parallel radioactive in vitro release studies using $\mathrm{Na}_{2}\left[{ }^{14} \mathrm{C}\right] \mathrm{EHDP}$ and additional studies in which the decrease in weight of the polymer rings was observed with time. The solubilized $\mathrm{Na}_{2}\left[{ }^{14} \mathrm{C}\right] E H D P$ was counted for radioactivity on a Beckman liquid scintillation counter (model 3801, Berkeley, CA).

\section{Tricuspid valve replacement in sheep}

Twenty-one sheep (6-7 \pm 3 months, male, Suffolk, 42-46 kg) underwent tricuspid valve replacement with Hancock I ( $25 \mathrm{~mm}$ ) bioprosthetic heart valves (Johnson \& Johnson Cardiovascular, Anaheim, CA). Autoclaved silicone rubber matrices were coimplanted with the BHV (Johnson et al., 1988). The matrices contained $\mathrm{Na}_{2}$ EHDP, $\mathrm{Na}_{2}$ EHDP : CaEHDP $(1: 1)$, or no drug. Data from two previous control animals were also compared with these implants (Levy, 1987b). Each matrix ring was placed around the stent posts of the bioprosthesis directly under the sewing cushion. Thus, periannular sewing ring sutures also secured the matrix to the prosthesis.

\section{Retrieval analysis}

At necropsy, the BHV's were removed and examined grossly, photographed, and then radiographed. A representative section of the valve cusp from the free edge to the point of attachment on the stent post was immediately fixed in a cacodylate-buffered $2.5 \%$ glutaraldehyde- $2 \%$ paraformaldehyde solution buffered at $\mathrm{pH} 7.2$ (Karnovsky, 1965) for $24 \mathrm{~h}$ and then dehydrated 
in graded ethanol solutions prior to embedding in glycolmethylmethacrylate (JB-4, Polysciences, Warrington, PA). Sections $(2-3 \mu \mathrm{m})$ were stained with hematoxylin and eosin for overall morphologic analyses and von Kossa's reagent for calcium phosphate (Levy et al., 1985b). The remaining portion of each cusp was prepared for quantitative analysis of calcium using atomic absorption spectroscopy (Levy et al., 1980 and 1983c). The polymeric drug delivery ring was detached from the sewing ring of the Hancock I bioprosthetic heart valve, weighed, and frozen until electron microprobe analysis.

Representative specimens of lung, liver, kidney, spleen, and myocardial tissue adjacent to the implant valves were also obtained at necropsy. Since systemically administered diphosphonates at doses of $15 \mathrm{mg} / \mathrm{kg} /$ day or more cause bone toxicity in rats (Levy et al., 1985b and 1987a), the proximal femoral head was removed from all control and treated sheep at necropsy. All specimens were stored in $10 \%$ neutral buffered formalin until the time of histologic analysis by light microscopy.

\section{Osmotic-mediated matrix expansion}

EHDP matrices of various compositions were formulated to study the effects on swelling of sealing $76 \%$ of the surface area of the matrices with drug-free polymer base, incorporating varying initial amounts of EHDP (20\% w/w vs $30 \%$ $\mathrm{w} / \mathrm{w})$, and varying the content of the less soluble calcium EHDP coincorporated with $\mathrm{Na}_{2}$ EHDP. The percent weight increase was monitored as a function of time with incubations at $37^{\circ} \mathrm{C}$ in a physiologic buffer $(0.10 \mathrm{M} \mathrm{NaCl}$ in $0.05 \mathrm{M}$ HEPES, $\mathrm{pH}=7.4$ ) and weighing the rings on a laboratory balance (Galaxy, Model G400, Florham Park, NJ).

\section{Thermomechanical analysis of polymeric implants}

A Metler thermomechanical analyzer (TMA) (Model TMA-40, Heightstown, NJ) was used to assess elastic properties of the various matrix formulations by applying standardized loads to linear segments of the polymer matrices. The Young's modulus (Y) was calculated for Silastic polymer (Silastic Q7-4840 and Silastic 382), with and without dispersed drug, as well as samples of explanted polymeric formulations retrieved after 5 months of circulatory implantation as part of sheep tricuspid valve replacements.

\section{Results and Discussion}

The present study demonstrated an absence of CALC in all EHDP controlled-release treated BHV's after 120-150 days (Table 1). However, only 2 of 7 non-treated explants were calcified, indicating deficiencies in the CALC model for testing this approach. Nevertheless, there was comparable EHDP release in vitro and in vivo, and matrix swelling was minimized through sealing $76 \%$ of the releasing surface with drug-free polymer and coincorporation of the poorly soluble calcium salt of EHDP. In addition, the Young's moduli for explanted matrices containing $\mathrm{Na}_{2}$ EHDP dispersed in Silastic Q7-4840 (20\% w/w) were noted to be less than non-drug containing Silastic Q7-4840.

\section{In vivo results}

Six of the 21 sheep were excluded from the study because of perioperative death. However,

TABLE 1

In vitro release and in vivo efficacy of silicone rubber-EHDP matrices after 20 weeks in the circulation of sheep

\begin{tabular}{|c|c|c|c|}
\hline $\begin{array}{l}\text { Drug/polymer } \\
\text { formulation }\end{array}$ & $\begin{array}{l}\% \text { EHDP } \\
\text { released } \\
\text { in vitro }^{a}\end{array}$ & $\begin{array}{l}\text { \% EHDP } \\
\text { released } \\
\text { in vivo } b\end{array}$ & $\begin{array}{l}\text { Tissue } \mathrm{Ca}^{2+} \\
(\mu \mathrm{g} / \mathrm{mg})\end{array}$ \\
\hline \multicolumn{4}{|l|}{ Control } \\
\hline Calcified & - & - & $\begin{array}{l}139 \pm 20.8^{c} \\
{[2]}\end{array}$ \\
\hline Non-calcified & - & - & $\begin{array}{l}2.07 \pm 0.27 \\
{[5]}\end{array}$ \\
\hline $\begin{array}{l}\mathrm{Na}_{2} \mathrm{EHDP} / \\
\text { silicone rubber }\end{array}$ & $\begin{array}{l}78.6 \pm 11.1 \\
{[6]}\end{array}$ & $\begin{array}{l}79.0 \pm 4.82 \\
{[5]}\end{array}$ & $\begin{array}{l}5.74 \pm 1.35^{d} \\
{[5]}\end{array}$ \\
\hline $\begin{array}{l}\text { Na-CaEHDP } \\
(1: 1) / \text { silicone } \\
\text { rubber }\end{array}$ & $\begin{array}{l}35.7 \pm 7.72 \\
{[6]}\end{array}$ & $40.4 \pm 9.68$ & $2.74 \pm 0.64$ \\
\hline
\end{tabular}

Numbers of determinations in parentheses.

a Determined by electron microprobe analysis, $\mathrm{Na}_{2}\left[{ }^{14} \mathrm{C}\right] \mathrm{EHDP}$ release, and reduction in matrix weight.

b Determined by electron microprobe analysis.

c From Levy et al. (1987b); values are mean \pm S.E.M.

d Includes 2 cases of bacterial endocarditis at 16 weeks. 
none of the sheep died as a result of prosthetic valvular dysfunction. Two additional sheep died suddenly at 16 weeks and were noted to have bacterial endocarditis. One additional animal was excluded from the EHDP controlled-release group due to sudden death and subsequent contamination of the explant. All of the remaining 12 animals ( 7 treatment, 5 control $(2$ of the 5 control animals are from Levy et al., 1987b)) were electively euthanized at 20 weeks.

None of the explanted BHV with drug delivery matrices had detectable CALC as determined by radiography, light microscopy, and leaflet $\mathrm{Ca}^{2+}$ analysis with atomic absorption spectroscopy (Table 1). However, only two of the 7 non-treated valves, from previous control animals, were calcified. Nevertheless, animals implanted with EHDP matrices demonstrated no detectable diphosphonate-related adverse effects, as determined by light microscopy of the femoral epiphyseal bone biopsies.

Although previous work (Levy et al., 1985b and c; Golomb et al., 1986a and b) had demonstrated that the controlled release of approximately 10-30 $\mu \mathrm{g} \mathrm{EHDP} /$ day/tissue leaflet (avg. tissue weight $=8 \mathrm{mg}$ ) was sufficient to inhibit CALC of bovine pericardial or porcine aortic tissue implanted subdermally in rats, it would be expected that larger amounts of EHDP would be required when delivered locally in the circulation. Although the amount (550-775 $\mu \mathrm{g}$ EHDP/day) of EHDP delivered in vivo in the present study was sufficient to inhibit BHV CALC (Levy et al., 1987a), efficacy could not be definitely assessed due to the sporadic calcification noted in the control group (Table 1). The present study confirms the large variability in the measured calcium leaflet concentration observed by others (Barnhart et al., 1982a) following tricuspid valve replacement in sheep.

Furthermore, the hemodynamic stresses affecting the orthotopic valve replacements in the tricuspid position in the present study might have contributed to lack of BHV CALC observed in explanted valves. Mitral valve replacements, which experience greater circulatory stresses, have been shown to calcify more extensively than tricuspid bioprostheses following implantation into the cir-

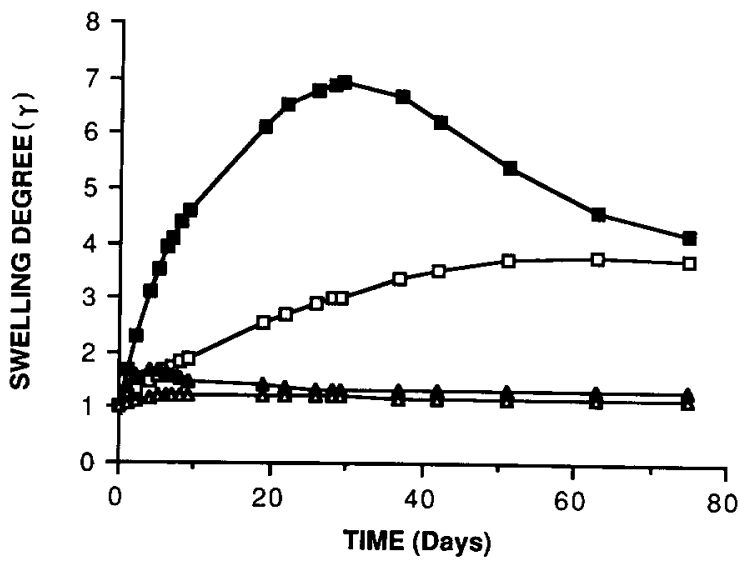

Fig. 2. Typical swelling degree vs time profile for silicone rubber-EHDP matrices. (匚), Unsealed matrix containing 30\% $\mathrm{w} / \mathrm{w} \mathrm{Na}{ }_{2} \mathrm{EHDP}$; ( $\square$ ), sealed matrix containing $30 \% \mathrm{w} / \mathrm{w}$ $\mathrm{Na}_{2}$ EHDP; (ム), unsealed matrix containing $30 \% \mathrm{w} / \mathrm{w} \mathrm{Na}$, CaEHDP $(1: 1) ;(\Delta)$, sealed matrix containing $30 \% \mathrm{w} / \mathrm{w} \mathrm{Na}$, CaEHDP $(1: 1) ; \gamma=$ swollen weight $/$ dry weight.

culation of juvenile sheep (Jones et al., 1986; Shemin et al., 1988).

\section{Osmotic-mediated matrix expansion}

Time-dependent matrix expansion due to osmosis-related fluid uptake was reduced in vitro by sealing $76 \%$ of the surface area of each matrix, and was further limited with coincorporation of CaEHDP as shown in Fig. 2.

The characteristic matrix swelling and deswelling stages reported by others (Di Colo et al., 1980, 1984, 1986; Carelli et al., 1986) were observed in the polymeric implants in the present study. Previous work by others has demonstrated that for water-soluble drugs dispersed in PDMS polymers, the extent of matrix swelling, $\gamma$, defined as the ratio of swollen to dry weight of a matrix containing a water-soluble additive, has been used to characterize stages of matrix swelling and matrix deswelling (Di Colo et al., 1980, 1984, and 1986; Carelli et al., 1986) (Fig. 2). Initially, as buffer, water, or physiologic fluids are osmotically taken up by the matrix, $\gamma$ increases. At some point in time, the value of $\gamma$ plateaus and then begins to decrease resulting in a parabolic curve when plotted against time of fluid uptake (Di Colo et al., 1980, 1984, and 1986; Carelli et al., 1986). The time for the value of $\gamma$ to reach a maximum value 


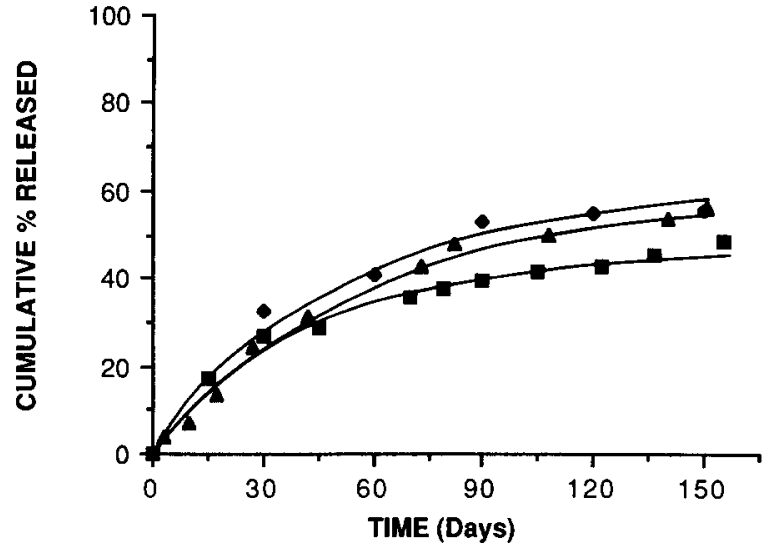

Fig. 3. Typical in vitro release profiles of EHDP from a silicone rubber-EHDP circular drug delivery matrix $[30 \% \mathrm{w} / \mathrm{w}$ $\mathrm{Na}, \mathrm{CaEHDP}(1: 1)]$ ( ), Determination by electron microprobe analysis; (A), determination by incorporation of $\mathrm{Na}_{2}\left[{ }^{14} \mathrm{C}\right] \mathrm{EHDP}$; (ם), determination by following overall matrix weight.

in the present in vitro studies ranged from 4 to 29 days (Fig. 2).

Sealed matrices explanted from sheep demonstrated osmotic-related swelling comparable to the in vitro results. The percent increase in weight of explanted sealed polymers were $162 \% \pm 34.5$ $\left(\mathrm{Na}_{2} \mathrm{EHDP}\right)$ and $69.5 \% \pm 1.35(\mathrm{Na}, \mathrm{CaEHDP})$ compared to $141 \%\left(\mathrm{Na}_{2} \mathrm{EHDP}\right)$ and $22.2 \%(\mathrm{Na}$, CaEHDP) for sealed polymer matrices studied in vitro, respectively.

\section{Controlled release of EHDP}

Matrices containing $\mathrm{Na}_{2}$ EHDP and CaEHDP $(1: 1)$ released in vitro less EHDP after 20 weeks than did those matrices containing only $\mathrm{Na}_{2}$ EHDP as determined by electron microprobe analysis, matrix weight change, and release of $\mathrm{Na}_{2}\left[{ }^{14} \mathrm{C}\right]$ EHDP.

A typical profile of the cumulative percent of drug ( Na, CaEHDP in Silastic $382(30 \% \mathrm{w} / \mathrm{w}))$ released in vitro over a 20 week period as determined by electron microprobe analysis is shown in Fig. 3. The 3 sealed areas of an individual cross-sectional specimen examined in vitro by electron microprobe analysis for EHDP release demonstrated background phosphorus levels versus time for all EHDP matrix formulations.
Thus, EHDP release from the matrix formulations proceeded in one dimension only.

In formulations where a $1: 1$ ratio of $\mathrm{Na}_{2}\left[{ }^{14} \mathrm{C}\right]$ EHDP : CaEHDP was incorporated in the polymer, the cumulative percent of $\mathrm{Na}_{2}\left[{ }^{14} \mathrm{C}\right]$ EHDP released from the matrix following 20 weeks incubation was in close agreement with the total percent of EHDP ( $\mathrm{Na}_{2} \mathrm{EHDP}$ and CaEHDP) released as determined by electron microprobe analysis. This would suggest that the less soluble CaEHDP undergoes a delayed dissolution and hence, negligible release from the matrix interior in the 20 week period. However, although no attempt was made in the present study to precisely quantitate the relative ratios of the $\mathrm{Na}_{2} \mathrm{EHDP}$ and CaEHDP that had been released, it can be noted in Fig. 3 that $\mathrm{Na}_{2}$ EHDP was the salt form primarily released from the $1: 1$ matrix formulations; the CaEHDP acting as a relatively less soluble coexcipient [ $\mathrm{Na}_{2}$ EHDP's aqueous solubility is approximately 1000 times that of CaEHDP (Golomb, G., Smith, M., unpublished data)]. The relative release rates of sodium EHDP and calcium EHDP in the formulation used in the present study have been previously described in detail (Golomb et al., 1987).

Previous research has shown that the mechanism of release for EHDP from silicone rubber occurs by absorption of a solvent/fluid into the matrix interior resulting in dissolution of the drug particles and subsequent diffusion of the drug from the polymeric matrix via a network of tortuous channels and pores created by dissolved drug particles (Golomb et al., 1986a; Levy et al., 1985c; Bawa et al., 1985). Neither $\mathrm{Na}_{2}$ EHDP nor CaEHDP are soluble in the hydrophobic silicone rubbers used in the present study (Golomb et al., 1986b and 1987; Levy et al., 1985b and c). Determination of the cumulative percent of EHDP released after 20 weeks by calculation of the decrease in matrix weight after drying to a constant weight, resulted in an approximate 7-10\% underestimation of total drug released compared to the percent EHDP released as determined by electron microprobe analysis (Fig. 3). Furthermore, it was assumed that the reduction in the initial weight of the ring, following oven-drying to a constant weight to remove buffer, was due to release of the 


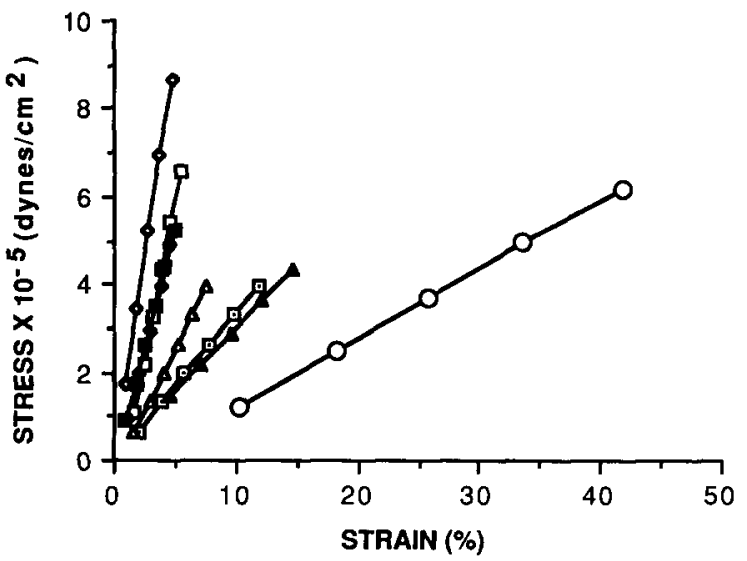

Fig. 4. Elasticity of controlled-release matrices. (O) EHDP-free Silastic 382; ( ), EHDP-free Silastic Q7-4840; (口), $\mathrm{Na}_{2} \mathrm{EHDP}$ dispersed in Silastic $382(20 \% \mathrm{w} / \mathrm{w}) ;(\diamond), \mathrm{Na}_{2} \mathrm{EHDP}$ dispersed in Silastic Q7-4840 (20\% w/w); (ש), Na-CaEHDP (1 : 1) in Silastic Q7-4840 (20\% w/w); (G), explanted specimen 1 (20\% $\mathrm{w} / \mathrm{w} \mathrm{Na}{ }_{2}$ EHDP in Silastic 382); (ه), explanted specimen 2 $\left(20 \% \mathrm{w} / \mathrm{w} \mathrm{Na}{ }_{2}\right.$ EHDP in Silastic Q7-4840); $(\Delta)$, explanted specimen $3(20 \% \mathrm{w} / \mathrm{w} \mathrm{Na}-\mathrm{CaEHDP}$ in Silastic Q7-4840).

dispersed active agent(s) and not due to deterioration or destruction of the cured silicone rubber polymer matrix.

In vivo explant analysis of EHDP matrices using electron microprobe analysis revealed 79.0 \pm 4.82 cumulative percent EHDP released for $\mathrm{Na}_{2}$ EHDP matrices and $40.4 \pm 9.68$ cumulative percent EHDP released for matrices containing Na-CaEHDP $(1: 1)$ after $120-150$ days. These results were comparable to the in vitro data (Table 1). However, as emphasized above and previously (Johnston et al., 1988), matrix CaEHDP would be expected to have continued to release for more than 2 years using the present formulation.

\section{Thermomechanical analysis of polymeric implants}

Thermomechanical analysis results revealed that the Young's moduli (Y), or slopes of the respective stress-strain curves as shown in Fig. 4, of EHDPSilastic matrices were greater than those measured in the non-drug containing Silastic samples. However, explanted matrices (20\% $\mathrm{w} / \mathrm{w} \mathrm{Na}{ }_{2}$ EHDP or $\mathrm{Na}-\mathrm{CaEHDP}$ in Silastic Q7-4840) were demonstrated to have values of $Y$ less than non-drug loaded Silastic Q7-4840, indicating perhaps, that the matrices explanted after 5 months in the circulation were demonstrating material fatigue.
While the greater stresses applied to the matrices implanted in the circulation were below the ultimate failure stress or yield stress, the continuous, cyclic stress-strain patterns may have resulted in the initiation of cracks or voids in the matrices (Schott, 1983; Sperling, 1986). On repeated stressing, these tiny flaws or cracks might have slowly propagated throughout the entire matrix, representing sites where ultimate failure or rupture of the polymer matrix could potentially occur. Extensive propagation of cracks or voids would result in a low tensile strength or weakening of the polymer matrix (Schott, 1983; Sperling, 1986). Weakening of the drug-loaded polymer matrix due to extensive propagation of cracks could potentially give rise to lower values of $\mathrm{Y}$ for explanted specimens.

Propagation of cracks or voids in a polymer matrix (20\% w/w Na ${ }_{2}$ EHDP in Silastic Q7-4840) arising from deformation due to osmotic-related swelling of the drug-loaded matrix would be expected to result in a much weaker polymer than a Silastic Q7-4840 matrix incorporating a $1: 1$ ratio of $\mathrm{Na}-\mathrm{CaEHDP}(20 \% \mathrm{w} / \mathrm{w})$. It can be noted in Fig. 4 that the explanted polymer matrices containing $20 \% \mathrm{w} / \mathrm{w} \mathrm{Na}-\mathrm{CaEHDP}$ dispersed in Silastic Q7-4840 had an approximate 20-fold larger value of $\mathrm{Y}$ than an explanted polymer specimen containing $20 \% \mathrm{w} / \mathrm{w} \mathrm{Na}{ }_{2}$ EHDP in Silastic Q74840. Thus, osmotic effects in the latter matrix composition may have contributed to an overall weakening of drug-loaded polymer matrices implanted in the circulation for 5 months as compared to non-implanted, control (non-drug loaded) Silastic Q7-4840 polymer.

\section{Strategies to inhibit BHV CALC}

Local, controlled release of diphosphonate into BHV implants for use in the circulation represents a novel approach to inhibit BHV CALC. It has been shown that localized, controlled release of diphosphonate (EHDP) using a 2-week osmotic pumping device (ALZET, Alza Inc., Stanford, CA) was effective at inhibiting BHV CALC at a dose of $5 \mathrm{mg} / \mathrm{kg} /$ day and was not associated with adverse effects (Levy et al., 1985b).

Once the effectiveness of locally delivered diphosphonate was established, the search for implant materials (biocompatible polymers) that 
would achieve a longer therapeutic duration was initiated. It was reported that EVA copolymer could be used for the controlled release $(>600 \mathrm{~h})$ of EHDP in vitro (Levy et al., 1985c). A further prolongation in drug delivery at a controlled rate has been demonstrated by judicious selection of initial drug load and drug solubility by coincorporation of the poorly soluble calcium salt of EHDP in polydimethylsiloxane (Golomb et al., $1986 \mathrm{~b}$ and 1987). Recent studies have been directed at still furthering drug delivery by appropriate membrane coating with non-drug containing polymer (Golomb et al., 1986b and 1987). All of these strategies have been effective in sustaining release of EHDP from various biocompatible polymeric matrices to inhibit BHV CALC.

\section{Conclusions}

The present study has demonstrated the novel use of controlled release EHDP for inhibition of BHV CALC in sheep. Advantage was taken of previous work (Golomb et al., 1986b and 1987) using the poorly soluble calcium salt of EHDP codispersed with $\mathrm{Na}_{2}$ EHDP in Silastic matrices to reduce osmotic-mediated matrix expansion and to potentially increase the duration of EHDP controlled release. Although efficacy could not be definitely assessed, matrix release in vivo corresponded with in vitro results, delivering dosages known to be efficacious in the rat subdermal model of BHV CALC without adverse side effects. Osmosis-related matrix swelling was successfully limited by surface sealing and coincorporation of CaEHDP. The Young's moduli of the explanted controlled-release matrices formulated with Silastic 382 were intermediate between those of drugloaded matrices and drug-free Silastic 382, indicating a return to a native viscoelastic state with in vivo release. However, explanted controlled release matrices fabricated using Silastic Q7-4840 appeared to have undergone material fatigue and weakening of the polymer matrix, especially matrices containing $20 \% \mathrm{w} / \mathrm{w} \mathrm{Na}{ }_{2}$ EHDP in Silastic Q7-4840 where osmosis-related matrix swelling might have contributed to the propagation of cracks and voids in the polymer matrix.

\section{Acknowledgments}

This work was supported, in part, by an American Heart Association, Michigan Affiliate Award (T.P.J.) 343048 and an NHLBI grant (R.J.L.) 5 RO1 HL38118 02. R.J.L. is an Established Investigator of the American Heart Association No. 860166. The authors are grateful to Dr. Kim P. Gallagher, Dr. David Rosen, Mr. Richard Bianco (University of Minnesota), and Dr. Michael Jones (National Institutes of Health) for advice on sheep open heart surgery. The authors are also grateful to Maria Lehto, Russel Grinage, and Michael Rudd for their assistance in all aspects of operating room procedure during tricuspid valve replacements, Helen Shing and Sara Murray, Brigham and Women's Hospital, Boston, MA, for assisting in the preparation of the tissue specimens for morphologic analysis, Dr. Raymond P. D'Alonzo of Norwich Eaton Pharmaceuticals, Inc., for providing sodium diphosphonate, Dr. James J. Benedict formerly of Proctor and Gamble, Inc., for providing $\mathrm{CaEHDP}$ and $\mathrm{Na}_{2}\left[{ }^{14} \mathrm{C}\right] \mathrm{EHDP}$, and Dr. William R. Pfister of Dow Corning, Inc., for providing Silastic polymers and Silastic-Dacron sheeting. We also thank Mrs. Catherine Wongstrom for her secretarial assistance and Mr. Ted Huff for creating Fig. 1.

\section{References}

Barnhart, G.R., Jones, M., Ishihara, T., Rose, D.M., Chavez, A.M. and Ferrans, V.J., Degeneration and calcification of bioprosthetic cardiac valves, Am. J. Pathol., 106 (1982a) 136-139.

Barnhart, G.R., Jones, M., Ishihara, T., Chavez, A.M., Rose, D.M., Ferrans, V.J., Failure of porcine aortic and bovine pericardial prosthetic valves: an experimental investigation in young sheep. Circulation, 66, Suppl. I (1982b) 1-50.

Bawa, R., Siegel, R.A., Marasca, B., Karel, M. and Langer, R., An explanation for the controlled release of macromolecules from polymers. J. Controlled Release, 1 (1985) 259-267.

Carelli, V., Di Colo, G. and Nannipieri, E., Effect of water-soluble additives on drug release from silicone rubber matrices. III. A study of release mechanisms by differential scanning calorimetry. Int. J. Pharm., 30 (1986) 9-16.

Di Colo, G., Carelli, V., Giannaccini, B., Serafini, M.F. and Bottari, F., Vehicle effects in percutaneous absorption: in vitro study of influence of solvent power and microscopic viscosity of vehicle on benzocaine release from suspension hydrogels. J. Pharm. Sci., 69, No. 4 (1980) 387-391. 
Di Colo, G., Campigli, V., Carelli, V., Nannipieri, E., Serafini, M.F. and Vitale, D., Release of osmotically active drugs from silicone rubber matrices. Il Farmaco-Ed. Pr., 39 (1984) 310-319.

Di Colo, G., Carelli, V., Nannipieri, E., Serafini, M.F. and Vitale, D., Effect of water-soluble additives on drug release from silicone rubber matrices. II. Sustained release of prednisolone from non-swelling devices. Int. J. Pharm., 30 (1986) 1-7.

Fishbein, M.C., Levy, R.J., Ferrans, V.J., Dearden, L.C., Nashef, A., Goodman, A.P. and Carpentier, A., Calcification of cardiac valve prostheses: biochemical, histologic, and ultrastructural observations in a subcutaneous implantation model system. J. Thorac. Cardiovasc. Surg., 83 (1982) 602-609.

Gallo, I., Nistal, F., Artinano, E., Fernandez, D., Cayon, R., Carrion, M. and Garcia-Martinez, V., The behavior of pericardial versus porcine valve xenografts in the growing sheep model. J. Thorac. Cardiovasc. Surg., 93 (1987) 281-290.

Golomb, G., Langer, R., Schoen, F.J., Smith, M.S., Choi, Y.M. and Levy, R.J., Controlled release of diphosphonate to inhibit bioprosthetic heart valve calcification: dose-response and mechanistic studies. J. Controlled Release, 4 (1986a) 181-194.

Golomb, G., Dixon, M., Smith, M.S., Schoen, F.J. and Levy, R.J., Inhibition of bioprosthetic heart valve calcification by sustained local delivery of $\mathrm{Ca}$ and $\mathrm{Na}$ diphosphonate via controlled release matrices. Trans. Am. Soc. Artif. Intern. Organs, 32 (1986b) 587-590.

Golomb, G., Dixon, M., Smith, M.S., Schoen, F.J. and Levy, R.J., Controlled-release drug delivery of diphosphonates to inhibit bioprosthetic heart valve calcification: release rate modulation with silicone matrices via drug solubility and membrane coating. J. Pharm. Sci., 76, No. 4 (1987) 271-276.

Johnston, T.P., Bove, E.L., Bolling, S.F., Boyd, J.A., Ciesliga, B.L., Schoen, F.J., Amidon, G.L. and Levy, R.J., Local controlled release of 1-hydroxylethylidene diphosphonate using silicone rubber matrices: effects of sterilization on in vitro release and in vivo efficacy, Trans. Am. Soc. Artif. Intern. Organs, in press.

Jones, M., Eidbo, E.E., Walters, S.M., Ferrans, V.J. and Clark, R.E., Effects of 2 types of preimplantation processes on calcification of bioprosthetic valves. In $\mathrm{E}$. Bodnar, and $\mathrm{M}$. Yacoub (Eds.), Biologic \& Bioprosthetic Valves: Proceedings of the Third International Symposium, Yorke Medical, New York, 1986, pp. 451-459.

Karnovsky, M.J., A formaldehyde-glutaraldehyde fixative of high osmolality for use in electron microscopy, J. Cell. Biol., 27 (1965) 137A-138A.

Levy, R.J., Zenker, J.A. and Lian, J.B., Vitamin K-dependent calcium binding proteins in aortic valve calcification, $J$. Clin. Invest., 65 (1980) 563-566.

Levy, R.J., Zenker, J.A., Barnhard, W.F., Porcine bioprosthetic valve calcification in bovine left ventricle-aorta shunts: studies of the deposition of vitamin $\mathrm{K}$-dependent proteins, Ann. Thorac. Surg., 36 (1983a) 187-192.
Levy, R.J., Schoen, F.J., Howard, S.L., Mechanism of calcification of porcine bioprosthetic aortic valve cusps: role of T-lymphocytes, Am. J. Cardiol., 52 (1983b) 629-631.

Levy, R.J., Schoen, F.J., Levy, J.T., Nelson, A.C., Howard, S.L., Oshry, L.J., Biologic determinants of dystrophic calcification and osteocalcin deposition in glutaraldehydepreserved porcine aortic valve leaflets implant subcutaneously in rats, Am. J. Pathol., 113 (1983c) 143-155.

Levy, R.J., Schoen, F.J., Howard, S.L., Levy, J.T., Oshry, M., Hawley, M., Calcification of cardiac valve bioprostheses: host and implant factors. In Rubin, R.P., Weiss, G.B. and Putney, J.W. Jr. (Eds.), Calcium In Biological Systems, Plenum Press, New York, 1985a, pp. 661-668.

Levy, R.J., Hawley, M.A., Schoen, F.J., Lund, S.A. and Liu, P.Y., Inhibition by diphosphonate compounds of calcification of porcine bioprosthetic heart valve cusps implanted subcutaneously in rats. Circulation, 71 (1985b) 349-356.

Levy, R.J., Wolfrum, J., Schoen, F.J., Hawley, M.A., Lund, S.A. and Langer, R., Inhibition of calcification of bioprosthetic heart valves by local controlled-release diphosphonate. Science, 228 (1985c) 190-192.

Levy, R.J., Schoen, F.J., Lund, S.A. and Smith, M.S., Prevention of leaflet calcification of bioprosthetic heart valves with diphosphonate injection therapy: experimental studies of optimal dosages and therapeutic durations. J. Thorac. Cardiovasc. Surg., 94 (1987a) 551-557.

Levy, R.J., Golomb, G. and Langer, R., Prevention of cardiovascular calcification with controlled-release diphosphonate. In Andrade, J.D. et al (Eds.), Artificial Organs, Proceedings of the International Symposium on Artificial Organs, Biomedical Engineering, and Transplantation, VCH, New York, NY, 1987b, pp. 657-669.

Milano, A., Bortolotti, U., Talenti, E., Valfre, C., Arbustini, E., Valente, M., Mazzucco, A., Gallucci, V. and Thiene, G., Calcific degeneration as the main cause of porcine bioprosthetic valve failure. Am. J. Cardiol., 53 (1984) 1066-1070.

Mykelbust, R.L., Fiore, C.E. and Heinrich, K.F.J., FRAME C: a compact procedure for quantitative energy-dispersive electron probe X-ray analysis. NBS Technical Note, 1106 (1979).

Schoen, F.J. and Levy, R.J., Bioprosthetic heart valve failure: pathology and pathogenesis, Cardiol. Clin., 2 (1984) 717-739.

Schoen, F.J. and Hobson, C.E., Anatomic analysis of removed prosthetic heart valves: causes of failure of 33 mechanical valves and 58 bioprostheses, 1980-1983, Hum. Pathol., 16 (1985a) 549-559.

Schoen, F.J., Levy, R.J., Nelson, A.C., Bernhard, W.F., Nashef, A. and Hawley, M., Onset and progression of experimental bioprosthetic heart valve calcification, Lab. Invest., 152 (1985b) 523-532.

Schoen, F.J., Cardiac valve prostheses: pathological and bioengineering considerations, J. Cardiovasc. Surg., 2 (1987) 65-108.

Schott, H., Polymer science. In A. Martin, J. Swarbrick, and A. Cammarata, A. (Eds.), Physical Pharmacy: Physical Chemical Principles in The Pharmaceutical Sciences, Lea and Febiger, Philadelphia, 1983, pp. 592-638. 
Shemin, R.J., Schoen, F.J., Hein, R., Austin, J. and Cohn, L.H., Hemodynamic and pathological evaluation of a unileaflet pericardial bioprosthetic valve. J. Thorac. Cardiovasc. Surg., 95 (1988) 912-919.

Sperling, L.H., Mechanical behavior of polymers. In Sperling,
L.H. (Ed.), Introduction To Physical Polymer Science, Wiley, New York, 1986, pp. 394-429.

Thurbrikar, M.J., Deck, J.D., Aouad, J., Nolan, S.P., Role of mechanical stress in calcification of aortic bioprosthetic valves, J. Thorac. Cardiovasc. Surg., 86 (1983) 115-125. 